\title{
Shear Strengthening of Reinforced Concrete Beams Using GFRP Wraps
}

\begin{abstract}
M. A. A. Saafan
The objective of the experimental work described in this paper was to investigate the efficiency of GFRP composites in strengthening simply supported reinforced concrete beams designed with insufficient shear capacity. Using the hand lay-up technique, successive layers of a woven fiberglass fabric were bonded along the shear span to increase the shear capacity and to avoid catastrophic premature failure modes. The strengthened beams were fabricated with no web reinforcement to explore the efficiency of the proposed strengthening technique using the results of control beams with closed stirrups as a web reinforcement. The test results of 18 beams are reported, addressing the influence of different shear strengthening schemes and variable longitudinal reinforcement ratios on the structural behavior. The results indicated that significant increases in the shear strength and improvements in the overall structural behavior of beams with insufficient shear capacity could be achieved by proper application of GFRP wraps.
\end{abstract}

Keywords: strengthening, shear capacity, GFRP, polyester, fiberglass, wrapping.

\section{Notation and symbols}

$$
\begin{aligned}
a & =\text { shear span from support to first concentrated load, } \\
& \text { mm } \\
A_{s}= & \text { longitudinal steel area, } \mathrm{mm}^{2} \\
b= & \text { beam width, mm } \\
d= & \text { beam effective depth, mm } \\
h_{w}= & \text { depth of the GFRP composite, } \mathrm{mm} \\
f_{c}= & \text { compressive strength of concrete, MPa } \\
f_{w a}= & \text { allowable tensile stress in the GFRP composite, MPa } \\
f_{w u}= & \text { ultimate tensile stress of the GFRP composite, MPa } \\
f_{y}= & \text { yield stress of reinforcement, MPa } \\
V_{c}= & \text { shear strength provided by concrete, } \mathrm{N} \\
V_{f}= & \text { beam shear capacity assuming flexural failure, } \mathrm{N} \\
V_{n}= & \text { nominal shear strength, MPa } \\
V_{s}= & \text { shear capacity provided by web reinforcement, } \mathrm{N} \\
V_{u}= & \text { ultimate shear load, } \mathrm{N} \\
V_{w}= & \text { shear strength provided by GFRP wraps, } \mathrm{N} \\
s & =\text { spacing of web reinforcement, mm } \\
t_{w}= & \text { thickness of the GFRP composite, mm } \\
\rho= & \text { reinforcement ratio }\left(A_{s} / b d\right)
\end{aligned}
$$

\section{Introduction}

Upgrading of reinforced concrete beams usually involves strengthening existing members to carry higher ultimate loads or to satisfy certain serviceability requirements. Strengthening of reinforced concrete members by bonding external steel plates using epoxy has been recognized to be an effective method for improving the structural performance. However, there have been two major disadvantages of this method: (a) difficulty in manipulating the steel plates at the construction site due to their bulk, and (b) deterioration of the bond caused by corrosion of the steel. These difficulties have led to the idea of replacing the steel plates by fiber-reinforced polymer (FRP) composites. Glass fibers are commonly used as a reinforcement offering unique advantages for GFRP composites, such as cost effectiveness, low density (one-quarter that of steel), resistance to electrochemical deterioration and low maintenance cost.
Reinforced concrete beams can be deficient in shear capacity due to a variety of factors including improper detailing of the shear reinforcement, poor construction practice, changing the function of the structure accompanied with higher service loads and a reduction in, or total loss of, the area of the shear reinforcement due to corrosion in a harsh environment. An innovative method of beam shear strengthening involves the use of FRP externally bonded to the faces of the member where the shear capacity is deficient. Several schemes are available: FRP plates bonded to the sides, strips of FRP bonded to the sides, or a jacket (wrap) placed along the shear span.

The literature showed that only a few studies have addressed the use of externally bonded FRP sheets to improve shear strength. Al-Sulaimani et al. [1] tested simply supported beams with fiberglass in different configurations (plates, strips and wraps) under four-point loading. The specimens were $150 \times 150 \mathrm{~mm}$ in cross section and $1250 \mathrm{~mm}$ long with a shear span to depth ratio equal to 3 . Compression and tension reinforcement as well as web stirrups were present. These beams were damaged before retrofit and were designed to fail in shear as the stirrups served mostly to confine the flexural reinforcement. The researchers determined that fiberglass plates and strips bonded to the sides of the beams produced a moderate $(25 \%-30 \%)$ increase in shear capacity. This repair technique, however, was not sufficient to prevent a shear mode of failure. Also, the fiberglass plates and strips peeled off. Beams fitted with a fiberglass wrap, however, nearly doubled the shear capacity of the beam, and this increase was sufficient to produce a flexural mode of failure. It was concluded that shear repair by a jacket on three sides performed better than repair by strips or wings. The wings of the jacket were well anchored at the bottom of the beam so that no premature peeling failure occurred. Additionally, the continuity provided by the geometry of the jacket minimized the effect of stress concentrations in the plates. Therefore, a jacket configuration should be considered whenever possible.

Chajes et al. [2] investigated reinforced concrete beams with aramid, glass, and graphite wraps loaded in four-point bending. These specimens were structural tees in cross section, having a $190 \mathrm{~mm}$ depth, $140 \mathrm{~mm}$ wide flange, a $64 \mathrm{~mm}$ thick web, and $1220 \mathrm{~mm}$ length. These beams were com- 
pletely lacking in shear reinforcement but contained enough flexural reinforcement so that a shear failure would occur. While all beams experienced an increase in ultimate capacity, they still failed in shear. The glass and graphite wraps were torn along the diagonal crack. The purpose of this experimentation was not to force flexural failure, but to determine the effectiveness of the system to increase the shear capacity in specimens that were designed to fail in shear. The FRP wrap was thus shown to be effective for shear repair. The work was continued in another research project [3], in which the beams were designed to fail in flexure, and this requirement was successfully fulfilled.

\section{Research significance}

Several studies have investigated the use of externally bonded FRP composites to improve the strength and stiffness of reinforced concrete beams, but most have addressed flexural strength, not shear. The efficiency of applying successive layers of fiberglass fabric as external shear reinforcements to enhance the shear capacity of RC beams without web reinforcement was investigated. The test parameters included a variable tension reinforcement ratio and different shear strengthening schemes. A combination of shear and flexural strengthening was also considered, aiming to achieve a further increase in ultimate loads accompanied by desirable ductile modes of failure. The efficiency of the proposed strengthening technique was evaluated making use of the test results for two groups of control beams. The beams in the first group were not strengthened and were fabricated with and without web reinforcement, while those in the second group were strengthened in flexure and were fabricated with and without web reinforcement. Simple equations describing the shear capacity of GFRP wraps were revised, based on the current results, to present a simple design tool for practicing engineers.

\section{Experimental program}

\subsection{Design considerations}

The design criteria for conventional beams were based on the provisions of ACI 318-95 Code [4] for ultimate strength design. The flexural and shear capacities were computed based on the actual material properties without using the reduction factors specified by the code. The code provisions for shear design use the concept that the nominal shear strength $V_{n}$ of a reinforced concrete member is taken as the sum of the shear carried by concrete $V_{c}$ and web reinforcement $V_{s}$. The term $V_{c}$ in a diagonally cracked beam represents three separate components: (a) dowel action of the tension longitudinal reinforcement, (b) aggregate interlock across the crack faces, and (c) shear carried by the uncracked concrete in the flexural compression zone [5]. The term $V_{s}$ represents the vertical component of the shear reinforcement across an assumed $45 \mathrm{deg}$. failure crack. The terms $V_{c}$ and $V_{s}$ are given by the ACI 318-95 Code as (Dim. in Ib and in.):

$$
\begin{aligned}
& V_{c}=\left(1.9 \sqrt{f_{c}^{\prime}}+2500 \rho V_{u} \frac{d}{M_{u}}\right) b d, \\
& V_{s}=A_{v} f_{y} \frac{d}{s} .
\end{aligned}
$$

According to the mathematical model proposed by Woo Kim [6], the term $V_{c}$ can be more accurately estimated for a beam under four point loading using the following equation taking into account the influence of the parameter $\mathrm{a} / \mathrm{d}$ :

$$
V_{c}=9.4\left[\sqrt{\rho}(1-\sqrt{\rho})^{2} \frac{d}{a}\right]^{\frac{1}{3}} \sqrt{f_{c}^{\prime}} b d .
$$

The design of beams strengthened in flexure by bonding GFRP composite of a specified thickness to the soffit of the beam was conducted according to the same design provisions of conventional beams. The strain in the extreme fiber of the concrete was set equal to 0.003 and the flexural capacity was computed using an iterative technique applying compatibility and equilibrium conditions.

The degree of shear strengthening required is represented by the difference between the load demand and the existing section capacity. The final shear capacity of the strengthened beam should be sufficiently higher than the flexural capacity to avoid shear failure modes, which can occur without warning and may be catastrophic. Shear strengthened beams were designed to carry an additional force $V_{w}$ according to the requirements specified by ICBO [7]. The design of the FRP wrap providing $V_{w}$ is based on controlling the shear crack width to maintain aggregate interlock and consequently proper shear transfer through the concrete. This requirement is fulfilled by limiting the allowable composite material stress, $f_{w a}$, to be 0.004 of the composite modulus of elasticity, $E_{w}$, but not more than 0.75 of the composite ultimate tensile stress $f_{w u}$. The shear force $V_{w}$ can be computed according to the following equation assuming a shear crack inclined at 45 degrees:

$$
V_{w}=2 t_{w} h_{w} f_{w a}
$$

in which $t_{w}$ is the thickness of the FRP composite and $h_{w}$ is its depth. The bond between the FRP composite and the underlying concrete surface should be capable of transmitting this shear force and consequently, a check for bond is necessary. Unfortunately, it is not straight forward to determine the loading level at which the bond is broken, because (a) the actual ultimate bond strength is influenced by many factors including the quality of the adhesive material, the quality of the surface preparation, and the efficiency of the fabric application process, (b) the distribution of shear along the depth of the composite is not generally uniform due to possible shear stress concentration at the composite ends, which causes it to peel off without developing the ultimate shear stress in a uniform distribution [4]. Al-Sulaimani et al. [4], pointed out that the ultimate shear strength can develop uniformly along the depth of the wings of strengthening jackets, as previously discussed. The shear force $V_{w}$ is related to bond stress when using side plates or jackets according to the following equation, assuming a shear crack inclined at 45 degrees [4]:

$$
V_{w}=\tau h_{w} d,
$$

where $\tau$ is the average shear stress developed along the interface. The actual value of the average stress can be estimated from the experiments by knowing ultimate shear force $V_{u}$ and the concrete shear capacity $V_{c}$ provided by control beams with no web reinforcement. However, for the purpose of preliminary design, the results provided by pulling double-lap FRP plates bonded to concrete provide a reasonable estimate for the average shear stress. 
Table 1: Description of test beams

\begin{tabular}{|l|l|c|l|}
\hline Group & $\begin{array}{c}\text { Beam } \\
\text { designation }\end{array}$ & $\begin{array}{c}\text { No. of } \\
\text { Beams }\end{array}$ & \multicolumn{1}{c|}{ Description } \\
\hline \multirow{2}{*}{ C } & $\mathrm{C} \phi \mathrm{W}^{*}$ & 3 & Control beams with steel web reinforcement \\
& $\mathrm{C} \phi$ & 3 & Control beams with no web reinforcement \\
\hline \multirow{2}{*}{$\mathrm{CF}$} & $\mathrm{CF} \phi \mathrm{W}$ & 3 & Control beams with steel web reinforcement and FRP wraps for flexural strengthening. \\
& $\mathrm{CF} \phi$ & 3 & Control beams with no web reinforcement and FRP wraps for flexural strengthening. \\
\hline \multirow{3}{*}{$\mathrm{S}$} & S $\phi \mathrm{FP}$ & 2 & Beams strengthened in flexure and in shear by side wraps forming side plates. \\
& S $\phi \mathrm{FU}$ & 2 & Beams strengthened in flexure and in shear by U-jacket wraps. \\
& S $\phi \mathrm{FR}$ & 2 & Beams strengthened in flexure and in shear by wraps around the whole cross section. \\
& S $\phi \mathrm{P} \& \mathrm{~S} \phi \mathrm{R}$ & 2 & Beams strengthened in shear by side plate wraps and wraps around the whole cross section. \\
\hline
\end{tabular}

* $(\phi)$ stands for the diameter of the reinforcing bar $(8,10,13 \mathrm{~mm})$

\subsection{Specimen details}

A total number of 20 singly reinforced concrete beams $(100 \times 150 \times 1050 \mathrm{~mm})$ were cast. All beams were reinforced with two lower bars allowing for an effective depth of $130 \mathrm{~mm}$. The beams were divided into three main groups according to the strengthening scheme (Table 1):

Group C: $\quad$ comprised six control beams without strengthening.

Group CF: comprised six control beams with flexural strengthening.

Group S: $\quad$ comprised eight beams with different schemes of shear strengthening.

Three out of six beams in group $\mathrm{C}$ and in group CF had different reinforcement ratios with vertical stirrups of $6 \mathrm{~mm}$ mild steel bars at $65 \mathrm{~mm}$ spacing as web reinforcement as, shown in Fig. (1.a). In order to determine the shear capacity provided by the concrete and to evaluate the efficiency of the external strengthening compared to steel as web reinforcement, the other three beams in groups $\mathrm{C}$ and $\mathrm{CF}$ were cast without stirrups. Table [2] reports the design details including the ratio of the ultimate shear capacity $V_{c}+V_{s}$ as a ratio of the ultimate shear force, $V_{f}$, associated with an assumed flexural failure. This ratio varied from 3.6 to 1.25 for beams with stirrups and from 0.33 to 0.88 for those without stirrups. The calculations in Table 2 show that Eq. (1) provided a conserva- tive estimate of $V_{c}$ compared to Eq. (3) according to which beam C8 was safe against shear failure.

The beams in group CF were typically the same as those in group C with FRP fabric adhered to the soffit of the beam. The FRP composite $(100 \times 800 \mathrm{~mm})$ consisted of eight layers of fabric with an overall thickness of $4 \mathrm{~mm}$, as shown in Fig. 1b. Testing the strengthened beams in group CF was intended to provide information about the beam behavior due to flexural strengthening and check out possible premature failure modes due to, for instance, composite debonding or concrete cover ripoff.

All beams in group $\mathrm{S}$ were without stirrups. The beams were strengthened in shear along the whole shear span length by wrapping the whole cross section, bonding rectangular side wraps $(130 \times 300 \mathrm{~mm})$, and bonding $\cup$-jackets, as demonstrated in Fig. 1c and 1d. Beams with 8 and $10 \mathrm{~mm}$ reinforcement bar diameter were also strengthened in flexural in the same way as in group CF. Table 3 summarizes the design calculations for shear strengthening based on the properties of the FRP material reported in Table 4 for different numbers of fabric layers and different composite thickness. Beams with a $13 \mathrm{~mm}$ reinforcement bar diameter were strengthened using four fabric layers in all shear repair schemes, while only two fabric layers were used in the other beams. Using ACI equations 1 and 2, the theoretical ratio $\left(V_{c}+V_{w}\right) / V_{f}$ assumes values between $1.42-2.52$ when side

Table 2: Details on control beams (group C)

\begin{tabular}{|c|c|c|c|c|c|c|}
\hline Beam & $A_{s}$ & $\rho / \rho_{b}$ & $V_{f}$ & $V_{c}$ & $V_{s}$ & $\left(V_{s}+V_{c}\right) / V_{f}$ \\
\hline $\begin{array}{c}\mathrm{C} 8 \mathrm{~W} \\
\mathrm{C} 8\end{array}$ & 100.53 & 0.19 & 13.64 & $12.06(17.69)^{*}$ & 36.74 & $\begin{array}{c}3.6(4.0) \\
-\end{array}$ \\
\hline $\begin{array}{c}\mathrm{C} 10 \mathrm{~W} \\
\mathrm{C} 10\end{array}$ & 157.08 & 0.28 & 20.39 & $12.49(18.74)$ & 36.74 & $\begin{array}{c}2.4(2.7) \\
-\end{array}$ \\
\hline $\begin{array}{c}\mathrm{C} 13 \mathrm{~W} \\
\mathrm{C} 13\end{array}$ & 265.46 & 0.68 & 40.09 & $13.31(19.95)$ & 36.74 & $\begin{array}{c}1.25(0.9) \\
-\end{array}$ \\
\hline
\end{tabular}

* ( ) $V_{c}$ value according to Eq. (3). 


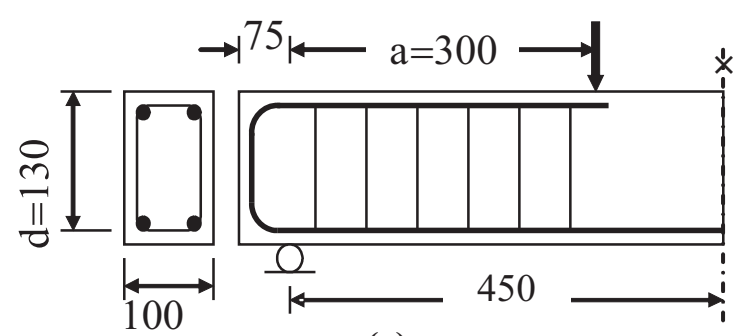

(a)

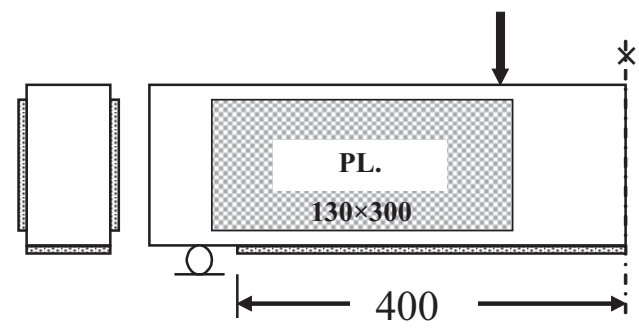

(c)

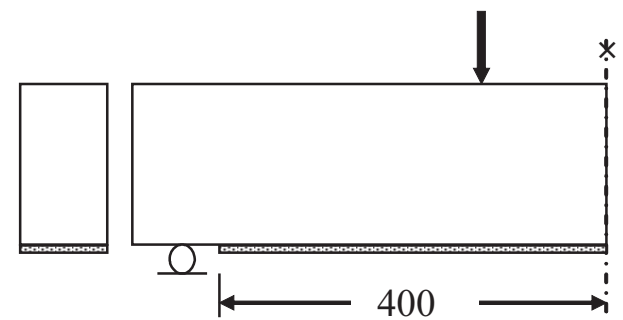

(b)

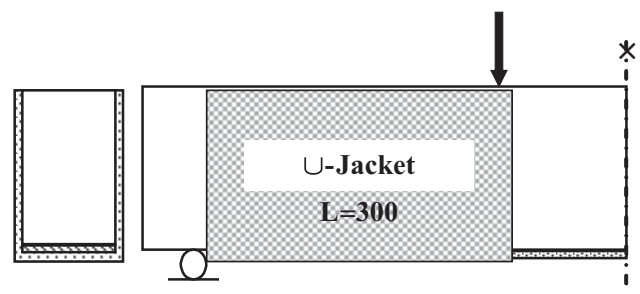

(d)

Fig. 1: Beam details and different repair schemes

plates are used and between 1.59-2.78 in the case of jackets, provided that the bond strength is sufficient so that $V_{w}$ can develop.

Table 3: Design calculations for shear strengthening

\begin{tabular}{|l|c|c|}
\hline No. of Fabric Layers & 2 & 4 \\
\hline Composite thickness $(\mathrm{mm})$ & 1 & 2 \\
Allow. tensile stress $(\mathrm{MPa})$ & 86 & 84 \\
Shear capacity $V_{w}(\mathrm{kN}):$ & & \\
$(1)$ side plates $\left(h_{w}=130 \mathrm{~mm}\right)$ & 22.4 & 43.7 \\
$\begin{array}{l}\text { (2) U-jacket or full wrapping } \\
\left(h_{w}=150 \text { mm) }\right.\end{array}$ & 25.8 & 50.4 \\
Required bond strength $(\mathrm{MPa})$ & 1.15 & 2.24 \\
\hline
\end{tabular}

\subsection{Fabrication of test beams}

The concrete mix was placed in the forms and vibrated to ensure consolidation of the concrete. The specimens were covered with wet burlap, which was kept moist for the first 3 days. The specimens were left to cure at room temperature and tested after 28 days of casting. Prior to application of the composite overlays, the beams were prepared by using a sand blasting machine to roughen the concrete surface to enhance the bond with the FRP composite and by rounding the corners of the beam along the shear span to a radius of $10 \mathrm{~mm}$. This practice was necessary to avoid bending the jacket wraps at a right angle and thus preventing the creation of gaps between the beam and the composite. The surfaces were then thoroughly cleaned of debris and dust using an air blower. The reinforcing fabric was cut to the proper dimensions using scissors, and was infused with polyester. This was done by laying the fabric over the soffit while the beam was upside down and spreading the resin by hand to saturate the fabric. For wrapping with $\cup$-jackets, it was found more convenient to saturate the fabric laid flat over a polyethylene sheet and then lay it up around the beam. To wrap the whole cross section, one layer in the form of a $\cup$-jacket was applied followed by an inverted jacket ( $\cap$ jacket).

\subsection{Instrumentation and test procedure}

All beams were tested to ultimate load in four-point bending over a simple span of $900 \mathrm{~mm}$ and a shear span of 300 $\mathrm{mm}$ providing a shear span-to-depth ratio $(a / d)$ of 2.3 . Both ends of the beam were free to rotate and translate under the load. The load was applied by means of a $100 \mathrm{kN}$ capacity flexural machine equipped with a digital control console. The load was applied in increments of $2.5 \mathrm{kN}$ until the tensile reinforcement yielded. Deflection control, in which the load step corresponds to a specified increase in deflection, was used when the beam entered the plastic range. The midspan deflection was recorded at each load step using a dial gage. Electrical resistance strain gages were affixed at the beam midspan section to monitor the strain internally in the tensile reinforcement and externally in the extreme concrete fiber in compression. Another two strain gages were located under the applied loads and affixed to the beam side $5 \mathrm{~mm}$ below the extreme compression fiber.

\subsection{Materials}

Concrete: a normal strength concrete mix with a specified 28-day compressive strength of $30 \mathrm{MPa}$ was made using natural gravel of a maximum size of $19 \mathrm{~mm}$ and Type I Portland cement. The cement:sand:gravel proportions in the concrete mix were 1:2:3.37 by weight and the water-cement ratio was 0.51 . Three cylinders $150 \times 300 \mathrm{~mm}$ and prisms $100 \times 100 \times 500 \mathrm{~mm}$ were cast and cured under the same conditions as the RC beams and tested at 28-days age to determine the average compressive strength, modulus of elasticity and modulus of rupture. The results are given in Table 4.

Steel: four different reinforcing bar sizes of mild and high strength steel were used as web and flexural reinforcements. Tension tests were conducted on full-size bar samples 
Table 4: Mechanical properties of concrete, reinforcement and FRP materials

\begin{tabular}{|c|c|c|c|c|c|c|c|}
\hline \multirow[t]{2}{*}{ Material } & \multicolumn{6}{|c|}{ Mechanical Properties (MPa) } & \multirow[b]{2}{*}{$\begin{array}{c}\text { Shear } \\
\text { strength }\end{array}$} \\
\hline & $\begin{array}{l}\text { Comp. } \\
\text { strength }\end{array}$ & $\begin{array}{l}\text { Mod. of } \\
\text { elasticity }\end{array}$ & $\begin{array}{l}\text { Mod. of } \\
\text { rupture }\end{array}$ & $\begin{array}{c}\text { Yield } \\
\text { strength }\end{array}$ & $\begin{array}{l}\text { Ultimate } \\
\text { strength }\end{array}$ & $\begin{array}{c}\text { Bond } \\
\text { strength }\end{array}$ & \\
\hline Concrete & 29.8 & 29500 & 2.6 & & & & \\
\hline \multicolumn{8}{|l|}{ Steel } \\
\hline$-\phi 6 \mathrm{~mm} *$ & & 200000 & & 325 & 475 & & \\
\hline$-\phi 8 \mathrm{~mm} *$ & & 210000 & & 330 & 462 & & \\
\hline$-\phi 10 \mathrm{~mm}^{*}$ & & 210000 & & 325 & 462 & & \\
\hline$-\phi 13 \mathrm{~mm}$ & & 210000 & & 420 & 625 & & \\
\hline Polyester & 102 & 1970 & 61.7 & & & 1.5 & 17.3 \\
\hline FRP comp. & & & & & & \multicolumn{2}{|c|}{ No. of fabric layers } \\
\hline$-1 \mathrm{~mm}$ thick. & & 21500 & & & 420 & \multicolumn{2}{|c|}{2} \\
\hline$-2 \mathrm{~mm}$ thick. & & 21000 & & & 311 & \multicolumn{2}{|c|}{4} \\
\hline$-4 \mathrm{~mm}$ thick. & & 18500 & & & 200 & \multicolumn{2}{|c|}{8} \\
\hline
\end{tabular}

*Plain mild steel bars

to determine the yield and ultimate strengths, as given in Table 4.

FRP: a commercially available fiberglass reinforced polymer matrix was used for beam strengthening as external shear and flexural reinforcement. The composite consisted of a number of layers of woven roving fiberglass embedded in a polyester resin. The fabric is made by weaving untwisted rovings in a plane weave (half of the strands are laid at right angles to the other half) with a nominal thickness of $0.5 \mathrm{~mm}$ and a density of $450 \mathrm{~g} / \mathrm{m}^{2}$. Tests were conducted to explore the mechanical properties of different locally available polymers including polyester, vinyl ester and epoxy adhesives. Based on these results, polyester was a convenient choice because of its excellent mechanical properties and relatively low price. Liquid polyester resin is cured with benzoyl peroxide as an initiator that was supplied in the form of an emulsion, as it may cause fire when used in a pure state due to rapid decomposition. An initiator dose of $8 \mathrm{ml} / \mathrm{kg}$ of polyester allowed for a curing time of 90 minutes before setting into a solid state in the mixing mold. The mixed amount was limited so that it can be applied with a brush without going into the gel state. The flexural prismatic specimen showed a major drawback in using polyester as an adhesive, as an average linear shrinkage as high as 2.5 percent was measured. It is however expected that the strain incompatibility problems, which are common and sometimes severe in plate bonding techniques due to autogenous shrinkage and thermal effects, should not be pronounced when using the wrapping technique. This is attributed to the very small thickness of the bonding line, which is reinforced at the same time by the fiber reinforcement.

Separate plates were manufactured to prepare the FRP specimens tested in tension. The plates were manufactured by laying the fabric layers out flat and evenly spreading the resin on the fabric by hand to saturate it. 24 hours later, three specimens were cut out of the plate and tested in uniaxial tension upon full cure. The material exhibited a linear elastic behav- ior up to failure with decreasing ultimate strength as the number of fabric layers and consequently the plate thickness increased. The average fiber content was $63 \%$ by weight ( $71 \%$ by volume) of the composite. Table 1 gives the results of the mechanical tests performed in accordance with ASTM specifications on both the FRP material and the polyester matrix. A special test arrangement was designed to evaluate the bond strength between the FRP composite and the underlying concrete surface. A concrete block $(100 \times 100 \times 400 \mathrm{~mm})$ provided with a wedge notch at the middle of the two opposite sides and two steel bars to be clamped in the testing machine. After the specimen has been pulled and split into two pieces at the notch location, the composite is adhered to the two faces with the notch to join the two pieces together. The composite was a strip $25.4 \mathrm{~mm}$ and extended $100 \mathrm{~mm}$ over one side of the notch and $200 \mathrm{~mm}$ over the other side.

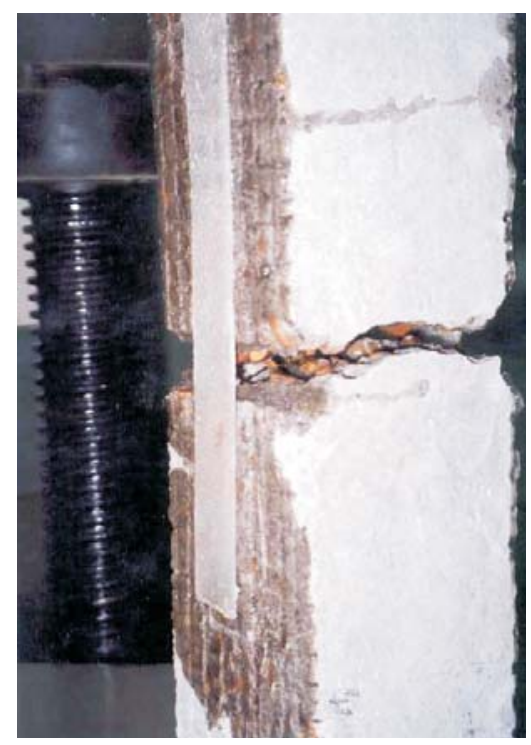

Fig. 2: FRP-concrete bond test 
Unequal extension about the notch was intended to force debonding of the composite to occur over a specified area. Three specimens were prepared in this manner and tested 72 hours later by pulling the specimen to the ultimate load at which the FRP strip peeled off (Fig. 2).

\section{Results and discussion}

The test results for eighteen beams are summarized in Table 5 , listing the measured cracking, yield and ultimate loads for the tested beams along with a description of the different modes of failure. Also, the load versus deflection curves for the tested beams are shown in Fig. 3 through 7. The load-deflection curves were terminated upon either sudden failure due to composite debonding or reaching an ultimate compressive strain of 0.003 associated with concrete crushing. Circular and triangular marks on the curves are used to indicate tension steel yielding and concrete crushing, respectively.

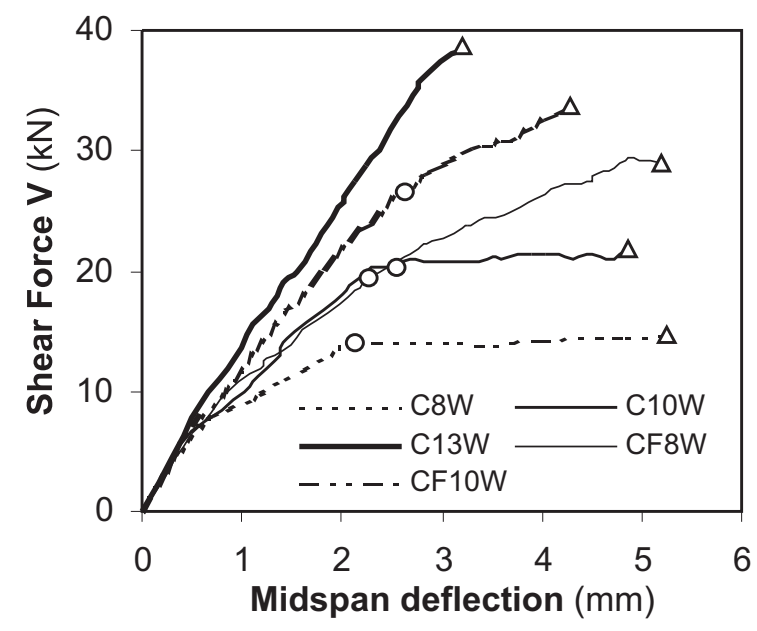

Fig. 3: Load-deflection curves for control beams with web reinforcement

The test results for the control beams in group $\mathrm{C}$ show that beams C8 and C10 failed in flexure, which means that the shear capacity was unexhausted and thus the ultimate shear force $V_{u}$ can only provide a lower bound for the concrete

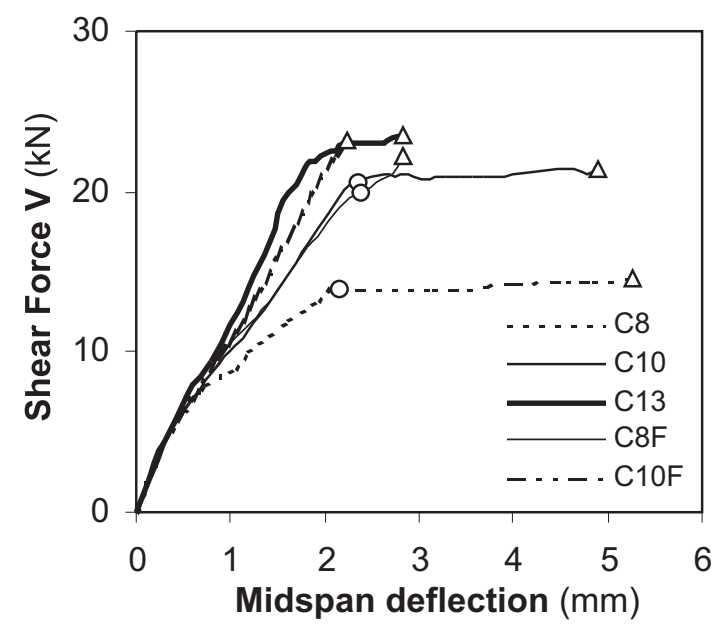

Fig. 4: Load-deflection curves for control beams with no web reinforcement

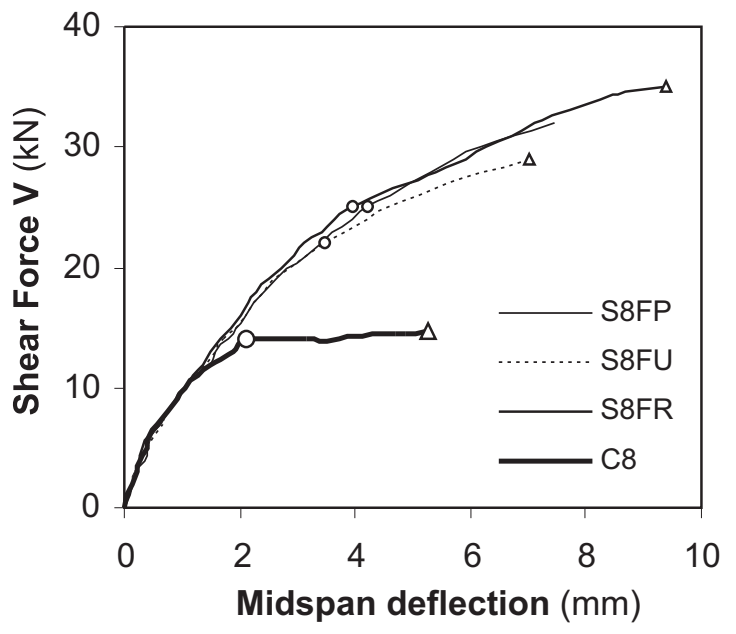

Fig. 5: Load-deflection curves for shear strengthened beams

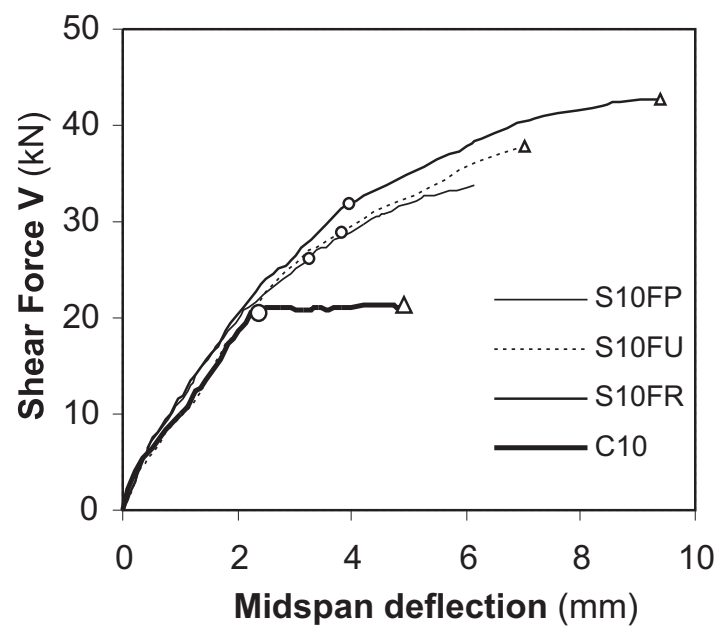

Fig. 6: Load-deflection curves for shear strengthened beams

shear capacity $V_{c}$. While the mode of failure for beam C13W was shear-compression, the shear capacity was also exhausted in beam C13, which failed due to diagonal tension. It can be concluded that Eq. (1) provided a highly conservative estimate for $V_{c}$ as its value was only 57 percent of the experimental value for beam C13. For beams C8 and C10 this ratio was 82 and 57 percent applying $V_{u}$ as a lower bound for $V_{c}$. The higher values for $V_{c}$ obtained by Eq. (3) provided a more accurate yet conservative prediction for the shear capacity. Diagonal tension failure modes always occurred due to a single crack extending throughout the shear span on one end of the beam. The crack started from the extreme flexure crack and gradually inclined with loading to finally approach the near point of loading with a flat slope. In shear-compression failures, the cracking pattern was almost symmetrical and was characterized by the extension of a flexural-shear crack towards the points of loading with web shear cracks connected to it. The web cracks started above the reinforcement level and extended towards the bottom of the beam.

The beams in group CF were strengthened in flexure by bonding eight successive layers of fiberglass fabric extending over 90 percent of the span. The aim of flexure strengthening was to provide additional flexural strength for group $\mathrm{C}$ beams so that shear failure and possibly other brittle modes would be 


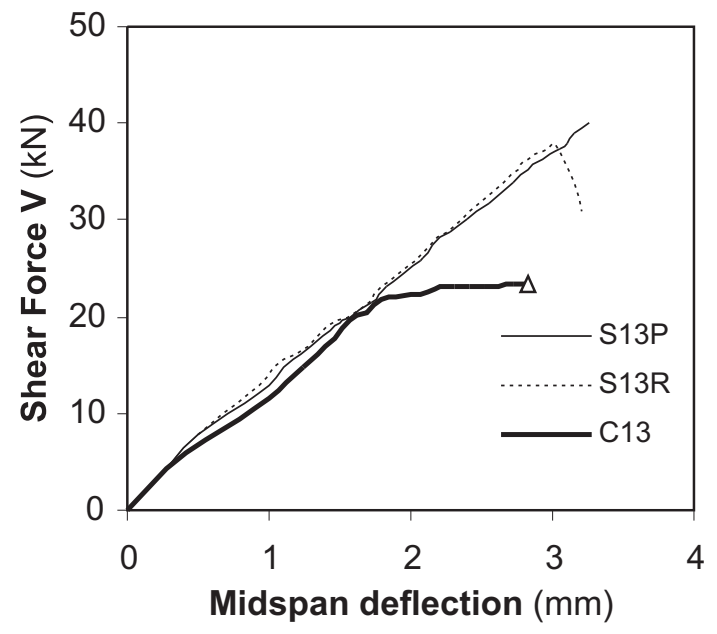

Fig. 7: Load-deflection curves for shear strengthened beams

expected. Because beam C13W failed in shear, it was not necessary to strengthen this beam in flexure and thus the results of only eighteen beams were reported. According to the proposed iterative solution, the flexural strength for beams CF8W and CF10W was 37.9 and $40.55 \mathrm{kN}$, respectively, making these two beams more likely to fail in shear with regard to their shear capacity. This was confirmed by the test results reported in Table 5. The mode of failure for beams CF8W and CF10W was shear-compression associated with simultaneous composite debonding. The beams showed suffi-

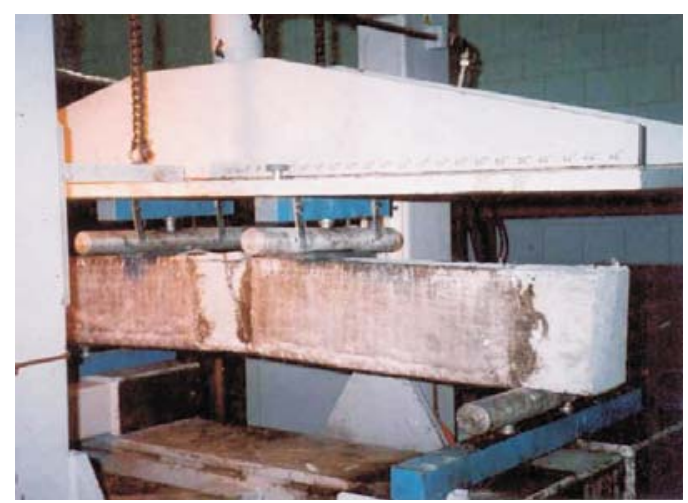

Fig. 8: Cambering of beam S8FU due to the initial tensile force in the FRP composite bonded to the soffit of the beam

cient ductility, as the tension reinforcement yielded at an earlier stage. It can be seen that there was no plateau in the load-deflection curves for these beams upon yielding, indicating that the increment in the tension component of the internal moment couple was carried by the composite after reinforcement yielding. The load carrying capacity for beams CF8W and CF10W was 96 and 55 percent higher than the ultimate loads of beams C8W and $\mathrm{C} 10 \mathrm{~W}$, respectively. The increase in the ultimate load for beams CF8 and CF10 compared to beams C8 and C10 was not as high as similar beams with web reinforcement. However, the mode of failure for these beams changed from flexure to diagonal tension due to flexural strengthening.

Table 5: Shear force $(\mathrm{kN})$ at different loading stages and mode of failure

\begin{tabular}{|c|c|c|c|c|c|}
\hline Group & Beam & $V_{c r}$ & $V_{y}$ & $V_{u}$ & Mode of Failure \\
\hline \multirow{6}{*}{$\mathrm{C}$} & C8W & 6.0 & 14.0 & 14.7 & Flexural (steel yielded) \\
\hline & C10W & 6.0 & 20.3 & 21.8 & Flexural (steel yielded) \\
\hline & C13W & 7.5 & - & 38.8 & Shear-comp. (onset of steel yielding \\
\hline & C8 & 6.0 & 14.0 & 14.7 & Flexural (steel yielded) \\
\hline & C10 & 6.0 & 20.6 & 21.4 & Flexural (steel yielded) \\
\hline & C13 & 8.0 & - & 23.5 & Diagonal tension (steel remained elastic) \\
\hline \multirow{4}{*}{$\mathrm{CF}$} & CF8W & 11.0 & 19.4 & 28.9 & \multirow{2}{*}{$\begin{array}{l}\text { Shear-compression associated with peeling of the FRP comp. (steel } \\
\text { yielded) }\end{array}$} \\
\hline & CF10W & 12.0 & 26.3 & 33.7 & \\
\hline & CF8 & 11.5 & 19.7 & 22.3 & Diagonal tension (steel yielded) \\
\hline & CF 10 & 12.0 & - & 23.2 & Diagonal tension (steel remained elastic) \\
\hline \multirow{8}{*}{$\mathrm{S}$} & S8FP & 16.0 & 25.0 & 32.0 & Debonding of lower plate (steel yielded) \\
\hline & S8FU & 15.0 & 22.0 & 29.0 & Flexural (steel yielded) \\
\hline & S8FR & 18.0 & 25.0 & 35.0 & $\begin{array}{l}\text { Steel yielding followed by rupture of the lower plate and concrete } \\
\text { crushing }\end{array}$ \\
\hline & S10FP & 17.0 & 27.2 & 33.7 & Debonding of lower plate (steel yielded) \\
\hline & S10FU & 17.0 & 29.0 & 37.9 & Flexural (steel yielded) \\
\hline & S10FR & 19.0 & 31.8 & 42.8 & $\begin{array}{l}\text { Steel yielding followed by rupture of the lower plate and concrete } \\
\text { crushing }\end{array}$ \\
\hline & $\mathrm{S} 13 \mathrm{P}$ & 13.0 & - & 38.0 & \multirow{2}{*}{ Debonding of side plates / jackets } \\
\hline & S13R & 13.0 & - & 40.0 & \\
\hline
\end{tabular}


Shear strengthening was planned to modify the mode of failure for control beams that failed in a brittle manner and to evaluate the associated increase in ultimate loads. The efficiency of the composite system as external shear reinforcement compared to web reinforcement can be assessed using the results for group $\mathrm{S}$ beams listed in Table 5. Compared to beam CF8W, the ultimate load was increased by 11,0 , and 21 percent in beams S8FP, S8FU, and S8FR, respectively. In all repair schemes, the ductility of the shear strengthened beams was superior to the control beams, as the steel yielded at an early stage of loading. The use of jackets in beam S8FU and full wrapping in beam S8FR effectively anchored the end of the lower plate and prevented it from peeling off. Beam S8FR developed the highest strength, as the lower plate was ruptured simultaneously with concrete crushing in the region of maximum moment. Surprisingly, beam S8FU did not gain any significant increase in the ultimate load compared to the control beam. Compared to beam S8FP, the mode of failure was modified into flexure while both stiffness and strength were superior in beam S8FP. This could be explained by the existence of unfavorable stress in the beam due to an initial eccentric tensile force in the lower plate. This particular beam was strengthened in shear by bonding the $\cup$-jackets 24 hours after bonding the lower composite. The lower plate was sufficiently cured by this time to resist the shrinkage associated with hardening of the matrix bonding the wing jackets. This force reduced the load carrying capacity of the beam and caused it to crack earlier. Concrete evidence in support of this explanation can be seen in the photograph in Fig. 8 showing cambering of the beam upon load release under the eccentric tensile force in the perfectly elastic lower composite plate. This argument suggested that the use of a high shrinkage matrix like polyester should be avoided or that it should be used with caution when the sequence of strengthening works is planned to avoid such a problem.

Compared to beam CF10W, the ultimate load was increased by 0,12 and 27 percent in beams S10FP, S10FU, and S10FR, respectively. It can seen that beam S10FP did not develop its full strength due to peeling of the lower plate, while beam S10FR yielded the highest strength as the lower plate ruptured at failure producing the maximum tensile force in the plate. Beams S13P and S13R, strengthened only in shear, developed 98 and 103 percent of the ultimate load developed by the control beam C13W. Failure of these beams was due to limited debonding of the side plates or wings over separate spots. Fig. 7 shows linear behavior for these two beams up to failure with a sudden drop in the load-deflection curves upon composite debonding.

To determine the shear capacity provided by different shear repair schemes, the shear capacity provided by the concrete was specified as provided by testing the control beams C13, CF8 and CF10. All these beams failed in shear and yielded an average concrete shear capacity of $23 \mathrm{kN}$. The two-layer composite in beam S10FR developed and sustained a load of $20 \mathrm{kN}$ with no signs of debonding. Similar computations showed that the 4 composite layers in beams S13P and S13R were useless, as a limiting bond stress of $0.77 \mathrm{MPa}$ governed. From the above discussions two major conclusions can be drawn. First, applying an external shear reinforcement using GFRP composites is as efficient as using closed stirrups as a web reinforcement with a possible improvement in the mode of failure. Second, the design guidelines outlined in Table 3 are satisfactory for external shear strengthening design when used along with the design equations of the ACI Code.

The load-deflection curves for all beams showed a minor improvement in beam stiffness due to flexural strengthening because of the small thickness and modulus of the composite. On the other hand, a remarkable increase in cracking loads was recorded. The tensile force generated in the composite when cracking was imminent effectively arrested the crack and also prevented it from opening up wide during all loading stages. A further increase in the cracking load was recorded in shear strengthened beams as the composite extended along the shear span (66 percent of the span) and thus the cracks were forced to occur along a limited portion of the beam.

\section{Conclusions}

The present study focused on performing a comprehensive experimental work to explore the efficiency of GFRP composites as an external shear reinforcement. The cost effectiveness of the system makes it a very attractive alternative in strengthening and repair works as the material are commercially available at a convenient price. The results indicated that significant increase in shear strength could be achieved by the application of GFRP to concrete beams deficient in shear capacity. When $\cup$-jackets are properly applied over the shear span, the failure mode of the beam may be altered from that of a brittle shear failure to a ductile flexural failure mode. Also, the strengthened beams were able to achieve the strength and stiffness levels of web reinforced beams. The results also show that the serviceability performance of strengthened beams is expected to be superior with regard to increased cracking loads and the limited number of cracks and small cracking width.

It was observed that the composite system was relatively difficult to adhere properly to the concrete prior to curing, as the fabric tended to separate. It was also noticed that the layers can easily to slip down under self weight. These difficulties suggest that suitable clamps are necessary to hold the system in place until curing. Also, the bond strength developing at the interface was a critical link in the strengthened beam. It was found difficult to avoid the existence of gaps near the edges when jackets are used despite the rounding of these edges along the shear span. These gaps are suspected to initiate bond failure, which may govern the ultimate strength of the beam. For this reason, special attention should be given to the preparation of the concrete surface, and to proper selection of the matrix and the placement of the fabric. Through proper design, GFRP composites developed sufficient ductility despite their brittle nature, which encourages their use as an effective concrete reinforcement. Finally, the cost effectiveness of the system makes it a very attractive alternative in strengthening and repair works, as the materials are commercially available at a convenient price.

\section{References}

[1] Al-Sulaimani, G. J., Sharif, A., Basunbul, I. A., Baluch, M. H., Ghaleb, B. N.: "Shear Repair for Reinforced Concrete by Fiberglass Plate Bonding." ACI Structural Journal, Vol. 91 (1994), No. 3, p. 458-464. 
[2] Chajes, M. J., Januszka, T. F., Mertz, D. R., Thomson, T. A., Finch, W. W.: "Shear Strengthening of Reinforced Concrete Beams Using Externally Applied Composite Fabrics." ACI Structural Journal, Vol. 92 (1995), No. 3, p. 295-303.

[3] Chajes, M. J., Thomson, T. A., Tarantino, B.: "Reinforcement of Concrete Structures Using Externally Bonded Composite Materials." In Proceedings Non-Metallic Reinforcement for Concrete Structures, 1995, E\&FN Spon., London, p. 501-508.

[4] ACI Committee 318: "Building Code Requirements for Reinforced Concrete, ACI-95 and commentary ACI 318R-95” ACI, 1995, p. 369.

[5] Johnson, M. K, Ramirez, J. A.: "Minimum Shear Reinforcement in Beams with High Strength Concrete." ACI Structural Journal, Vol. 86 (1989), No. 4, p. 376-382.

[6] Woo Kim, White, R. N.: "Initiation of Shear Cracking in Reinforced Concrete Beams with no Web Reinforce- ments." ACI Structural Journal, Vol. 88 (1991), No. 3, p. 458-308.

[7] International Conference of Building Officials Evaluation Service, ICBO “Acceptance Criteria for Concrete and Reinforced and Unreinforced Masonry Strengthening Using Fiber-Reinforced Composite Systems" AC125, 1997.

Dr. Mohamed Abdel Aziz Saafan e-mail:m.safan2000@yahoo.com

Department of Civil Engineering

Faculty of Engineering

Menoufia University

Egypt 